\title{
TREATMENT EDUCATION OF LEXICAL AND GRAMMATICAL DISORDERS'S CONSTRUCTIONS IN PATIENTS WITH LOCAL BRAIN LESIONS
}

\author{
Vladimirovna, V.G \\ Kazan (Volga region) Federal University
}

\begin{abstract}
There is a need to form rehabilitation and correctional programmes for dyslexic people. This research aim is to study the problem of treatment of lexical and grammatical disorders' formations in a daily care hospital treatment conditions. The speech function of patients with local brain lesions was analysed using method of dominant verbal functions' evaluation (V.M. Schklovsky, T.G. Vizel). Treatment of disorders of lexical and grammatical constructions was deducted by the specially developed model of a treatment education in group and individual sessions with the use of different methods and assumptions chosen in accordance with the condition of the speech function of patients. The data analysis of the follow up speech function assessment after treatment education has revealed the significant improvement of the level of grammatical speech construction. Results of the research aimed to investigate the effectivity of the model of treatment of lexical and grammatical constructions in patients with local brain legions in a daily care hospital treatment has shown the positive dynamics of the treatment education as a result of the developed model of treatment.
\end{abstract}

Keywords: Aphasia, treatment education, expressive agrammatism, lexical and grammatical constructions

\section{INTRODUCTION}

The problem of education for treatment of aphasia draws growing attention of researchers from different fields: logopedia, neuropsychology, linguistics, psycholinguistics and others. From one side, the interest to this problem is based on the importance of her investigation for the advanced knowledge about brain functioning mechanisms, about the link between speech and brain, about its psychophysiological bases, about interrelationship between speech and other psychological processes; from the other side the growing interest to this area of knowledge is based on her social and practical importance due to the questions of full recovery of functioning of these patients $[1,2,6,7]$.

In studies of many scientists and practitioners analyzing methods of treatment of the speech function of patients with local brain lesions it is noted that at certain degree expressive agrammatism is present to all forms of aphasia. This is most prevalent in acousticomnestic and motor aphasia according to classification of aphasia of A.R.Liria [4]. There is a dysfunction of lexical and grammatical speech construction coincident with these forms of aphasia. Patients at certain degree experience difficulties of expressing their own opinions, reconstruction of the content of texts from study books. The narration of the texts is accompanied by phrase construction's difficulties. This is explained by the dysfunction of those speech operations responsible for the grammatical constructioning [3].

Aspects of treatment of lexical and grammatical site of a speech in adults with local brain lesions are researched in works of T.V. Ackhunina, T.G. Vizel, N.M. Pylaeva, L.S. Zvetkova, V.M. Shklovsky, M.K. Shohor-Trozkaya and other scientists. The main aim of the treatment education of the expressive agrammatism is overcoming of dysfunctions of grammatical structuring $[1,2,4]$.

Corresponding author email: GVValiullina@kpfu.ru 
One of the possible approaches to the solution of this task is presented in this article based on the example of the treatment of lexical and grammatical constructions in patients with local brain lesions going through rehabilitation in the department of the treatment therapy GAUZ «Hospital for veterans of war» of Naberezhnye Chelny city, Republic of Tatarstan, the Russian Federation.

\section{EXPERIMENTAL RESEARCH ON ASSESSMENT AND TREATMENT OF THE LEXICAL AND GRAMMATICAL CONSTRUCTIONS IN PATIENTS WUTH THE LOCAL BRAIN LEGIONS}

Experimental research on assessment and treatment of the lexical and grammatical constructions in patients with the local brain legions was conducted in the department of the treatment therapy GAUZ «Hospital for veterans of war» of Naberezhnye Chelny city, Republic of Tatarstan, the Russian Federation.

Aim of research was to reveal lexical and grammatical speech disorders in patients with local brain legions, develop a model of phrase speech treatment in this category of patients.

With this aim there were selected 30 post-stroke patients aged 30-60 years. Among them: 12 patients with residual mixed aphasia: acousticomnestic combined with the efferent motor aphasia and 18 patients with the residual motor aphasia. These patients had gone through the neuropsychological assessment (based on methodic of T.G.Vizel, V.M.Shklovsky et al., 1992) to determine neuropsychological status and topic diagnosis for each patient, given quantitative speech evaluation allowing determining the degree of speech disorders, also there was investigated the peculiarity of lexical and grammatical constructions' use with these patients.

Due to the fact that object of the research were peculiarities of the grammatical speech row construction that can be researched only on the basis of the phrasal speech requiring formation of word forms, the experimental group was formed from the number of selected earlier patients having safe phrasal level of verbal communication (moderate and light degree of speech disorders based on neuropsychological assessment and quantitative speech evaluation). In the research participated 10 post-stroke patients aged 40-60 years with expressive agrammatism. Among them: 4 patients with residual mixed aphasia: acousticomnestic combined with the efferent motor aphasia and 6 patients with the residual motor aphasia.

Assessmetn was conducted based on methodics of neuropsychological research of psychic functions (T.G.Vizel, V.M.Shklovsky et al., 1992) [7].

Based on this methodic, in observed patients the level of safety of use of following skills was analyzed: case-ending, grammatical categories of subjective, grammatical categories of pronoun and time of verb, gender, prepositions. Total five tests were offered. The evaluation was made by 10 -point scale.

During the assessment of the speech function of participants there were revealed difficulties in choice of lexical and grammatical expressions of thoughts as well as in its combination. The disorder of the lexical and grammatical speech construction is based on the disintegration of those speech operations, during which the grammatical structuring is made. In patients were noted mistakes in the use of lexical and grammatical constructions, presented in table №1 «Lexical and grammatical speech disorders» and on the picture 1 «Condition of grammatical speech in patients with expressive agrammatism before and after the treatment therapy». 
Table 1: Lexical and grammatical speech disorders

\begin{tabular}{|c|c|c|c|c|c|c|}
\hline $\begin{array}{l}\text { Patients } \\
\text { (initials) }\end{array}$ & $\begin{array}{l}\text { Singular and plural } \\
\text { nouns (in relative } \\
\text { cases) }\end{array}$ & $\begin{array}{l}\text { Singular and plural verbs } \\
\text { (present., past simple) }\end{array}$ & $\begin{array}{l}\text { Sentence and case } \\
\text { constructions }\end{array}$ & $\begin{array}{l}\text { Sequence: noun with adjective, } \\
\text { with numeral adjective, with } \\
\text { verb (in plural) }\end{array}$ & $\begin{array}{l}\text { Construction of simple } \\
\text { sentences }\end{array}$ & $\begin{array}{l}\text { Construction of } \\
\text { complex sentences }\end{array}$ \\
\hline V.N. & $\begin{array}{l}\text { Mistakes in use of } \\
\text { plural nouns of } \\
\text { subjects }\end{array}$ & $\begin{array}{l}\text { Confuses nouns of past } \\
\text { tense verbs }\end{array}$ & $\begin{array}{l}\text { Uses all prepositions } \\
\text { with mistakes }\end{array}$ & $\begin{array}{l}\text { Doesn't match subjectives with } \\
\text { adjectives }\end{array}$ & $\begin{array}{l}\text { Doesn't use the right } \\
\text { consequence }\end{array}$ & Not available \\
\hline V.D. & $\begin{array}{l}\text { Difficulties } \\
\text { aroused }\end{array}$ & $\begin{array}{l}\text { Difficulties of past verbs } \\
\text { use }\end{array}$ & $\begin{array}{l}\text { Don't use right (in, } \\
\text { from, under, above) }\end{array}$ & $\begin{array}{l}\text { Subjectives with numeral } \\
\text { adjectives and adjectives }\end{array}$ & uses & Doesn't make \\
\hline Z.V. & Incorrectly uses & Incorrectly uses & $\begin{array}{l}\text { Incorrectly use of } \\
\text { prepositions }\end{array}$ & $\begin{array}{l}\text { Match subjectives with } \\
\text { adjectives with difficulties }\end{array}$ & Finds it difficult & $\begin{array}{l}\text { Doesn't use in } \\
\text { narrative }\end{array}$ \\
\hline Z.U. & $\begin{array}{l}\text { uses plural nouns } \\
\text { in gender and case } \\
\text { not correctly }\end{array}$ & $\begin{array}{l}\text { Doesn't tell plural tense of } \\
\text { verbs }\end{array}$ & $\begin{array}{l}\text { Difficulties of use of } \\
\text { all prepositions }\end{array}$ & $\begin{array}{l}\text { Subjectives with adjectives, with } \\
\text { numeral adjectives }\end{array}$ & Uses with mistakes & $\begin{array}{l}\text { Has difficulties in } \\
\text { construction of } \\
\text { complex dependent } \\
\text { sentences }\end{array}$ \\
\hline V.S. & Has difficulties & $\begin{array}{l}\text { Mistakes in use of plural } \\
\text { tense of verbs }\end{array}$ & $\begin{array}{l}\text { Doesn't know } \\
\text { prepositions (above, } \\
\text { under, from, } \\
\text { between) }\end{array}$ & $\begin{array}{l}\text { Subjectives with numeral } \\
\text { adjectives and adjectives }\end{array}$ & $\begin{array}{l}\text { Doesn't follow } \\
\text { consequence }\end{array}$ & $\begin{array}{l}\text { has difficulties in } \\
\text { construction of } \\
\text { complex sentences }\end{array}$ \\
\hline
\end{tabular}


Vladimirovna, V.G / Treatment Education of Lexical and Grammatical Disorders's Constructions....

\begin{tabular}{|c|c|c|c|c|c|c|}
\hline M.L. & $\begin{array}{l}\text { Mistakes in use of } \\
\text { singular tense in } \\
\text { different clauses }\end{array}$ & Difficulties aroused & $\begin{array}{l}\text { Confuses simple } \\
\text { prepositions, doesn't } \\
\text { know complex } \\
\text { prepositions }\end{array}$ & $\begin{array}{l}\text { Don't match subjective with } \\
\text { numeral adjective and verb }\end{array}$ & Makes up with difficulties & $\begin{array}{l}\text { Doesn't use with the } \\
\text { speech with the } \\
\text { scenario }\end{array}$ \\
\hline K.R. & $\begin{array}{l}\text { Difficulties } \\
\text { aroused }\end{array}$ & $\begin{array}{l}\text { Has difficulties with use of } \\
\text { past tense }\end{array}$ & $\begin{array}{l}\text { Incorrectly uses (in, } \\
\text { from, under, above), }\end{array}$ & $\begin{array}{l}\text { Subjectives with numeral } \\
\text { adjectives and adjectives }\end{array}$ & uses & Doesn't make \\
\hline I.K. & Finds it difficult & $\begin{array}{l}\text { Has mistakes in use of } \\
\text { plural tense of verbs }\end{array}$ & $\begin{array}{l}\text { doesn't know } \\
\text { prepositions (above, } \\
\text { under, from, } \\
\text { between) }\end{array}$ & $\begin{array}{l}\text { Subjectives with numeral } \\
\text { adjectives and adjectives }\end{array}$ & $\begin{array}{l}\text { Doesn't follow } \\
\text { consequence of words }\end{array}$ & $\begin{array}{l}\text { Has difficulties in } \\
\text { construction of } \\
\text { complex sentences }\end{array}$ \\
\hline V.I. & $\begin{array}{l}\text { uses plural nouns } \\
\text { in gender and case } \\
\text { not correctly }\end{array}$ & $\begin{array}{l}\text { Doesn't name plural tenses } \\
\text { of verbs }\end{array}$ & $\begin{array}{l}\text { Difficulties in use of } \\
\text { all prepositions }\end{array}$ & $\begin{array}{l}\text { Subjectives with adjectives, with } \\
\text { numeral adjectives }\end{array}$ & Uses with mistakes & $\begin{array}{l}\text { Has difficulties in } \\
\text { construction of } \\
\text { complex dependent } \\
\text { sentences }\end{array}$ \\
\hline V.G. & $\begin{array}{l}\text { Difficulties } \\
\text { aroused }\end{array}$ & $\begin{array}{l}\text { Has difficulties with use of } \\
\text { past tense verbs }\end{array}$ & $\begin{array}{l}\text { Incorrectly uses (in, } \\
\text { from, under, above), }\end{array}$ & $\begin{array}{l}\text { Subjectives with numeral } \\
\text { adjectives and adjectives }\end{array}$ & Uses & Doesn't make \\
\hline
\end{tabular}


From data shown in table №1 and picture 1 it is seen that based on the relevantly variable speech there is not precise meaning and use of many general terms. In the active dictionary of patients there are prevalent subjectives and verbs. There are little words, characterising qualities, features, conditions of objects and actions. Patients make majority of mistakes e in use of simple prepositions (in, on, under, with). Also there were many violations of grammatical language forms - mistakes in sentence cases, mixing up of time and types of verb tenses, in arrangement and management and difficulties of words construction. In active speech there are mainly used simple sentences. There are noted major difficulties, and often complete inability to distribute and make complex sentences. In all patients are noted difficulties in the replay of words of complex syllable structure. In some patients disabled temporary and logical connections in narrative: shuffle parts of the tale, miss important elements of the scenario.

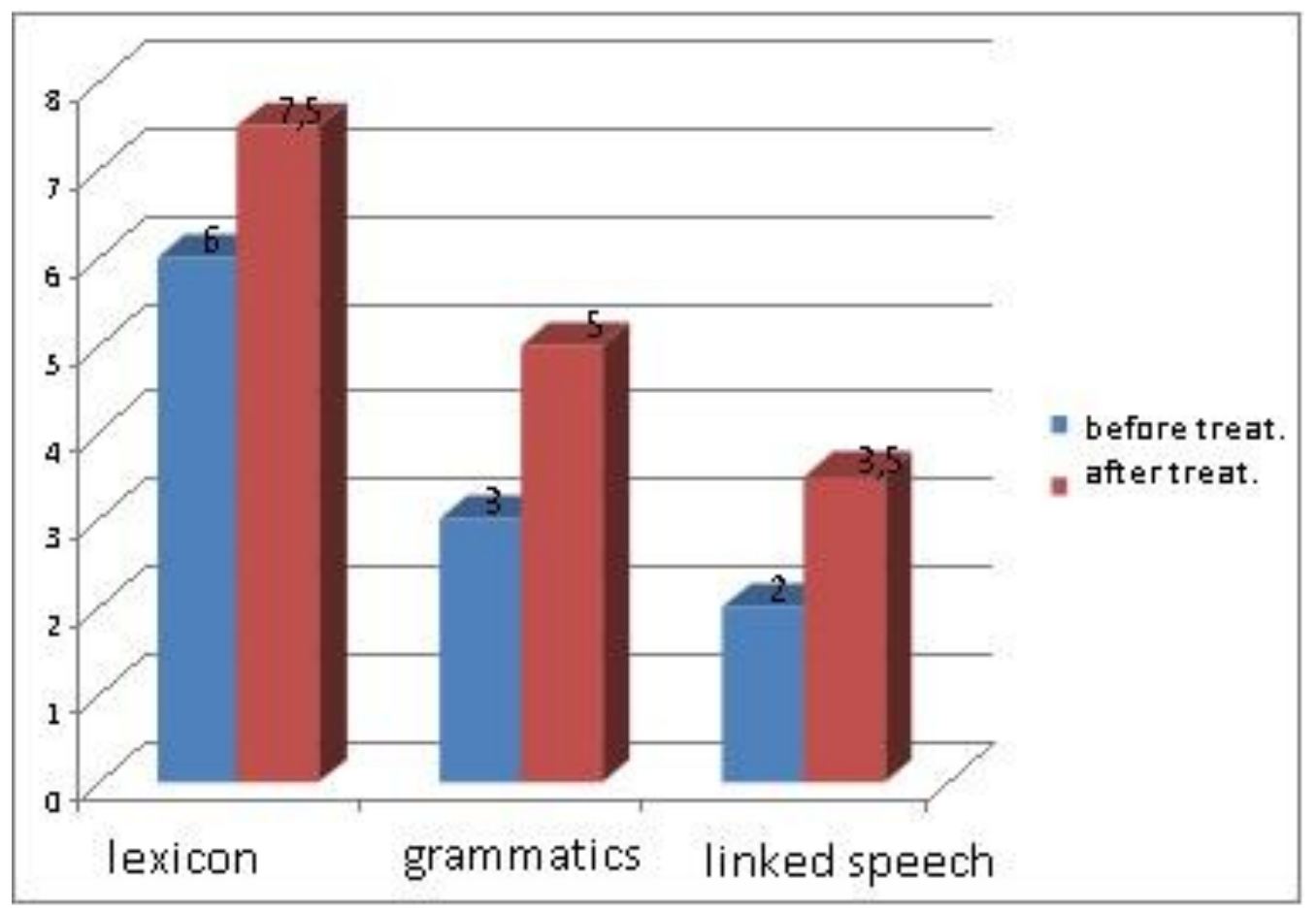

Picture 1. Condition of grammatical speech in patients with expressive agrammatism before and after the treatment therapy.

In accordance with the logopedic conclusions there were developed individual rehabilitation programmes for each patient. Programs were based on the important for treatment education principle of consistency. This means, that treatment procedures must be conducted for all sites of disabled function and not only for those that were most destroyed at first.

Programs included following directions of treatment:

- reconciliation of breathing;

- afferentation in the speech cerebral regions (electrophonopedical stimulation on the apparatus «vokastim»);

- overcoming of the pronounce site of speech disorders;
- Restitution of the phrasal speech.

Overcome of the lexical and grammatical disorders' constructions was made on the basis of the specially developed model of treatment education (Pic. 2) during group and individual lessons with the use of different methods and methodics, chosen in accordance with the condition of a speech function of patients.

The reconstruction of the phrasal speech in patients with local brains legions included two directions of therapeutic work according to the model presented on Pic.2:

1. Restitution of word change of nouns, verbs, adjectives.

2. Treatment education on the level of phrase, sentence, linked speech. 
Restoration of words change was initiated in two stages. During the first stage there was conducted the logopedic work on reconstruction of the skills to make afferentation of nominative plural or singular case and also, ability to coordinate nouns and verbs of present tense of singular third case. Also workout of non-sentence constructions was conducted at the first stage.

Logopedic treatment of the lexical site of speech was conducted at the first stage. Special attention was devoted to the verbal lexicon to reconstruct categories of predictive in phrase. The second stage of rehabilitation included treatment of word changing skills for nouns, verbs and adjectives. The next stage of rehabilitation was conducted at the level of phrases, sentences, linked speech.

Ontogenetic principle was in the core of the treatment of grammatical structure of speech and, in particularly, forming of the grammatical row in ontogenesis. By this reason the word changing operation skill's reconstruction was maintained in patients firstly in phrases, then in sentences, and then in the linked speech.

Based on the methodic of R.I.Lalaeva the following types of phrases were kept in mind during rehabilitation: a) based on verbs, b) named.

The special attention in the rehabilitation of patients with expressive agrammatism was devoted to verb phrases. From one side this was based on the fact that the verb very often serves as a predicate, organising parts of the sentence and, from another side, in these patients it is prevalently predicative that fall down from the structure of sentence. 


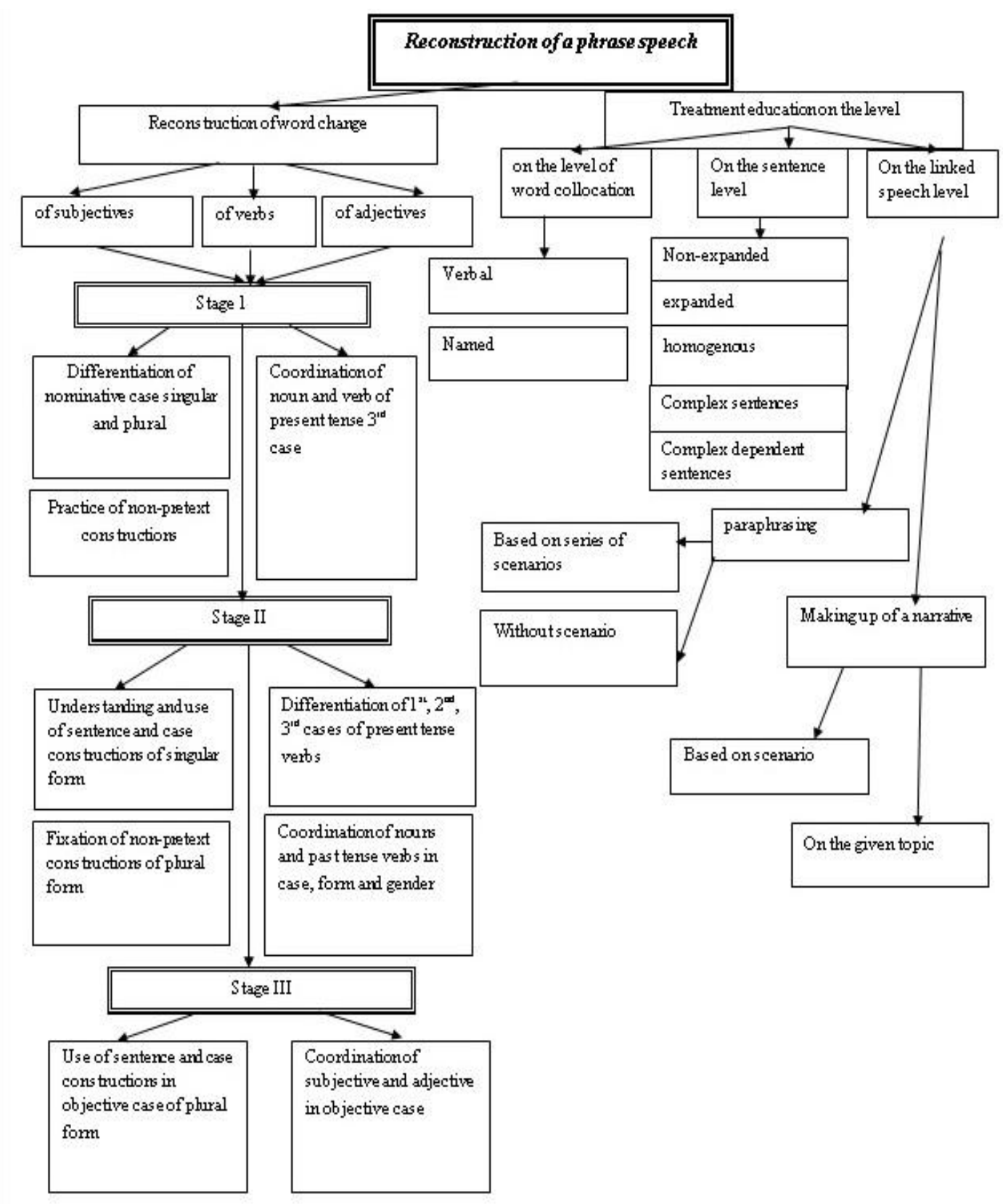

Pic.2: Model of reconstruction of a phrase speech in patients with the local brain legions

During the treatment education aimed at maintaining forms of the word change in sentences the semantic complexity of one or another model of the sentence was brought in mind and also the consequence of the appearance of the types of sentences in ontogenesis.

During the process of word changing forms' fixation in the linked speech the consequence of the rehabilitation was determined by the complexity of the semantic structure of text, types of texts.
There were used 3 main types of text: narrative text, text-description, text-reasoning. For the treatment therapy in patients with expressive agrammatism it is mainly used narrative text and text-description. Narrative text is the simplest text for this category of patients demonstrating dynamics of events.

The visual representation was widely used for each type of the text during the initial stage.

The fixation of the word change in the linked speech was based on the self-management of linked 
Vladimirovna, V.G / Treatment Education of Lexical and Grammatical Disorders's Constructions....

statements that determines the following consequence:

- paraphrasing of simple and short texts with series of scenarios with preliminary practice of the content of each scenario;

- retellings of series of scenarios without preliminary practice of the content of each scenario.

- retellings based on scenario with the preliminary practice of its content by questions;

- retellings based on scenario without preliminary discussion of its content;

- retelling without scenarios;

- making up of the tale based on series of scenarios after preliminary discussion about content of each scenario;

- making up of the tale based on scenarios without preliminary practice of its content;

- making up of the tale based on scenario with the preliminary discussion about its content;

- making up of the tale based on scenario without preliminary discussion about its content;

- making up of the tale on the give topic.

Differentiation of the grammatical form was conducted in the following consequence:

- The comparison of object, features, actions based on scenarios, selection of differences in real situations.

- Selection of the common grammatical meaning of the row of word bases in impressive speech.
- Matching up marked meanings with flexion.

- Phonemic analysis of selected flexion.

- The written labelling of flexion.

- Fixation of the link between grammatical meaning and flexion in phrases.

- Fixation of the form of word change in sentences and linked speech.

The method of visibility was used in different types: subject pictures, scenario pictures, paired pictures, schemes for making tales. Different types of games, exercises and tasks were held during treatment lessons.

To determine the effectivity of the conducted treatment education at the end of the treatment we have conducted the control testing of the lexical and grammatical row of speech for patients of the department of the treatment therapy GAUZ «Hospital for veterans of war» of Naberezhnye Chelny city, Republic of Tatarstan, the Russian Federation using methodics before treatment. In the result of the processing of statistical data of the post-treatment assessment the following results were revealed: there found an increase of the level of the grammatical row of speech. Post-treatment data are presented on Pic. 1 and Pic.3. 


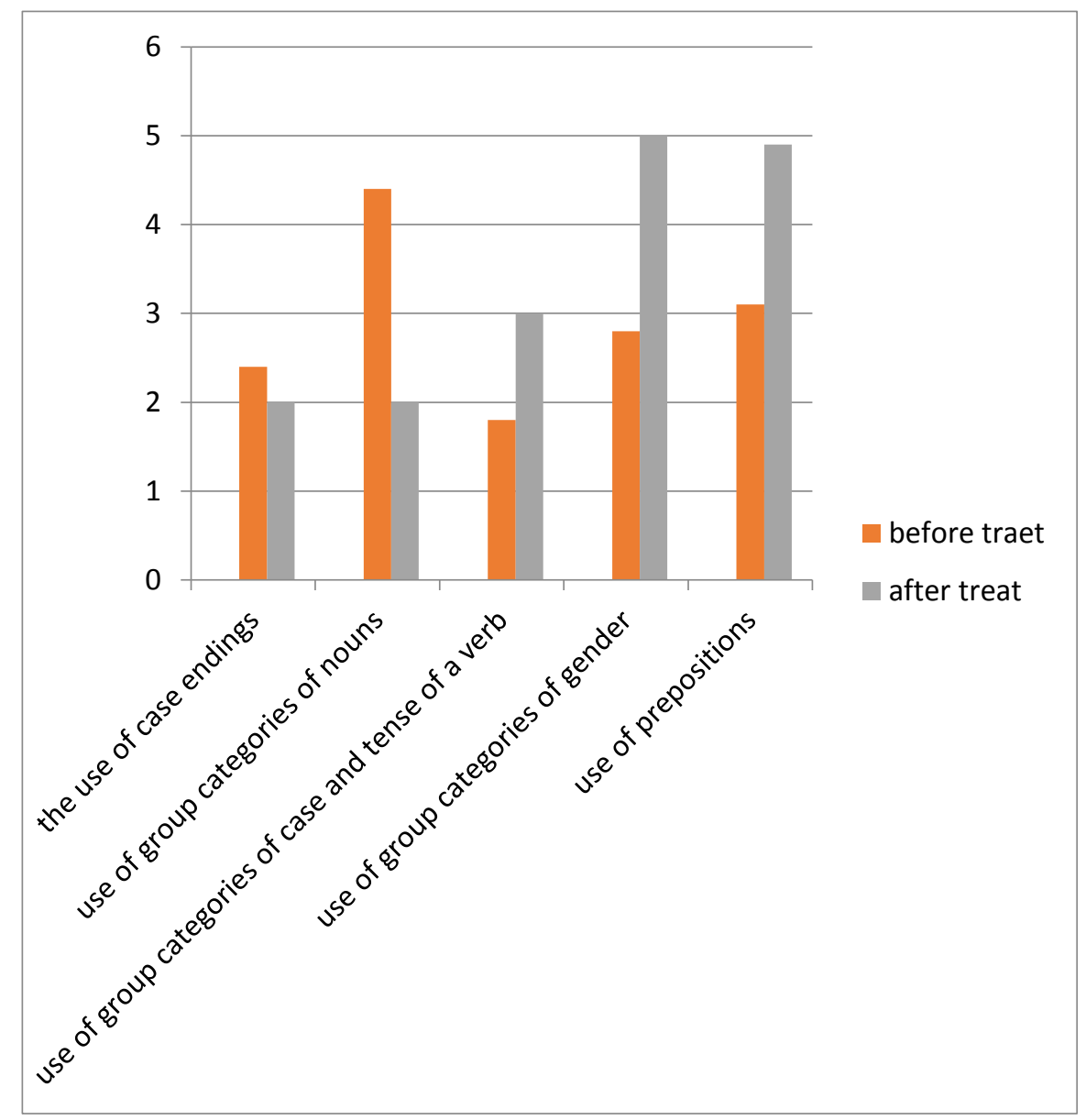

Picture 3. Dynamics of reconstruction of the grammatical speech in patients with the expressive agrammatism.

\section{RESULTS}

Patients successfully learned the treatment program according to the developed by us model. In general, there was observed increased level of speech skills in patients. There was noted a tendency of increase of lexicon in the speech status of patients, appearance of homogenous terms of sentence included in the structure of the complex sentence. Many patients in the independent speech started using different grammatical constructions. However, yet patients mixed up compound linking words and tried avoiding their use in the spontaneous speech. The was improved linked speech. However, yet there were left shortcomings in the differentiation of the simple pronouns, use of compound pronouns, compound sentences. Therefore, all patients were given recommendations for continuing treatment with the speech therapist.

To conclude, we have received the positive dynamics after methodically correctly organised therapy and systematisation of the material for the reconstruction of the lexical and grammatical constructions with the active use of the visual and didactical material.

\section{CONCLUSIONS}

Analysis of results of the control testing of the lexical and grammatical speech row has shown that the developed by us treatment model of the reconstruction of the phase speech in patients with the local brain legions is an effective and can be used in the treatment of the speech in named category of patients.

\section{ACKNOWLEDGEMENT}

We would like to thank the department of the treatment therapy GAUZ «Hospital for veterans of war» of Naberezhnye Chelny city, Republic of Tatarstan, the Russian Federation for help during organisation of the experiment. The work is performed at the expense of the grant allocated to Kazan federal university to perform the state task in the sphere of scientific activity. Author confirms that 
this research doesn't cross with research interest of other authors.

\section{REFERENCES}

Akhmetzyanova, A. I. (2015). Fear and Anxiety in the Children Suffering from Infantile Cerebral Palsy and Raised in Families with Various Parental Subsystems. Asian Social Science, 11(7), p356. doi:10.5539/ass.v11n7p356 .

Akhrnetzyanova, A. I. (2015). Anticipation and Prediction Interrelation Neuropsychological Mechanisms at Youthful Age. The Social Sciences, 10(4), 399-401. doi 10.3923/sscience.2015.399.401.

Bein, E. S. (1964). Aphasia and the ways of its overcoming. Medicine. Leningrad's department.
Gazizulina, D.S. (2009). Comparative analysis of condition of the vertebran and non-vertebral components of morphological code of the language in patients with aphasia. Logopedia, 4 (26). - P. 21-26.

Lalaeva, R. I. and Serebrakova, N. V. (1999). Correction of basic underdevelopment of the speech in preschool children (formation of the lexical and grammatical row of speech). S-Pb.: Soyuz.

Shohor-Trockaya, M.K. (2001). Strategy and tactics of the speech reconstruction. Moscow.

Vizel, T. G. (2005). Basis of the nevropatology: study book for students of dialectological and psychological faculties. M. AST: Astrel: Transitkniga. 